\title{
Raising Beet Tolerance to Salinity through Bioaugmentation with Halotolerant Endophytes
}

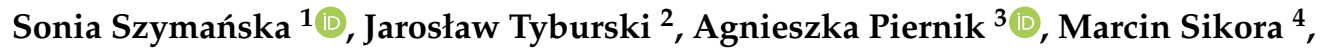 \\ Justyna Mazur ${ }^{4}$ and Hrynkiewicz Katarzyna ${ }^{1, *}$ \\ 1 Department of Microbiology, Faculty of Biological and Veterinary Sciences, Nicolaus Copernicus University, \\ Lwowska 1, 87-100 Torun, Poland; soniasz@umk.pl \\ 2 Chair of Plant Physiology and Biotechnology, Faculty of Biological and Veterinary Sciences, \\ Nicolaus Copernicus University, Lwowska 1, 87-100 Torun, Poland; tybr@umk.pl \\ 3 Chair of Geobotany and Landscape Planning, Faculty of Biological and Veterinary Sciences, \\ Nicolaus Copernicus University, Lwowska 1,87-100 Torun, Poland; piernik@umk.pl \\ 4 Center for Modern Interdisciplinary Technologies, Nicolaus Copernicus University, Wileńska 4, \\ 87-100 Toruń, Poland; sikoramar@umk.pl (M.S.); justyna.mazur@umk.pl (J.M.) \\ * Correspondence: hrynk@umk.pl; Tel.: +48-56-611-25-40
}

Received: 13 September 2020; Accepted: 12 October 2020; Published: 15 October 2020

\begin{abstract}
Increasing land salinization in recent decades has led to a decrease in crop productivity worldwide. We hypothesized that bioaugmentation of beetroot (Beta vulgaris) with halotolerant endophytic bacterial strains isolated from the obligatory halophytic plant Salicornia europaea L. may mitigate salt stress in new host plants. Therefore, we investigated the effects of inoculation with Pseudomonas stutzeri ISE12 or Kushneria marisflavi CSE9 on B. vulgaris growth in substrates enriched with various $\mathrm{NaCl}$ concentrations $(0,50,150,300 \mathrm{mM})$. The results of this study indicated that bioaugmentation with either bacteria resulted in improved growth parameters and increased chlorophyll content, as well as decreased proline and hydrogen peroxide concentrations, in B. vulgaris organs. However, K. marisflavi CSE9 was more efficient in achieving salt stress mitigation than P. stutzeri ISE12. In conclusion, the range of salinity tolerance seems to be a key parameter in the selection of strains for beet inoculation. The selected halotolerant endophytes (P. stutzeri ISE12 and K. marisflavi CSE9) isolated from the roots of obligatory halophytic S. europaea may be employed for plant growth promotion, especially in saline areas, and have potential applications in sustainable agriculture.
\end{abstract}

Keywords: PGPE—plant growth-promoting endophyte; salt stress; Beta vulgaris; Kushneria marisflavi; Pseudomonas stutzeri

\section{Introduction}

The beginning of the 21st century has been marked by increasing global scarcity, environmental pollution and salinization of arable soil and water resources [1]. It is estimated that 800 million ha of land in the world (nearly 7\% of all land) has been degraded by salinity, including 32 million ha (40\%) of all agricultural land [2-4]. Soil is recognized as saline when its electrical conductivity in solution reaches $4 \mathrm{dS} \mathrm{m}^{-1}$ (equivalent to approximately $40 \mathrm{mM} \mathrm{NaCl}$ ) [5]. Soil salinity can be a consequence of natural (e.g., geological and hydrological changes) or anthropogenic processes (such as deforestation and irrigation using saline water) [6,7]. Salinity negatively affects the physiology and biochemistry of plants and results in reduced crop productivity [8,9]. The response of plants to salt stress depends on the species, variety and phase of plant growth [6]. Only a small group of plants, the halophytes, can tolerate salinity exceeding $200 \mathrm{mM} \mathrm{NaCl}$, while most known terrestrial plants (and the majority of arable crops) are glycophytes that have the ability to grow only in a slightly saline environment. Possible means of increasing salinity tolerance of crops are the domestication of halophytes or the 
application of plant growth-promoting endophytic (PGPE) bacteria isolated from halophytes for the bioaugmentation of plants.

In our work, we investigated beetroot (Beta vulgaris rubra), which is a descendant of the halotolerant sea beet (Beta vulgaris subsp. maritima L.). This popular crop is commonly cultivated in America, Europe and Asia [10]. B. vulgaris is used in the production of juices, marinades and salads. Due to the presence of sugar, mainly sucrose, it is also a component of energy drinks for athletes [10]. Betalains contained in the roots are widely used in the food, cosmetics and pharmaceutical industries [11]. This popular vegetable is a good source of many phytochemical compounds, including carotenoids, phenolic acids, ascorbic acid and flavonoids, and it possesses antioxidant, anti-inflammatory and anticancer effects [10-12]. Beets have exhibited a therapeutic effect on many diseases, e.g., hypertension, atherosclerosis, type 2 diabetes and dementia [12]. Due to the origin and socioeconomic importance of beets, $B$. vulgaris is considered a good model for research, primarily in the context of salt stress $[12,13]$.

Salt stress causes many changes in plant morphology that can be observed at all stages of plant growth and development [1]. The earliest effects can be observed at the stage of seed germination and seedling growth [14-16]. Further effects of salinity can be manifested by the limitation of plant growth, reduction of leaf area, length of shoots and roots, disturbance of the flowering process, decrease in the number and size of fruits, and reduction of fresh and dry weight $[1,14,16-18]$.

The response of plants to salt stress can also be observed and determined based on changes in biochemical parameters [16]. Salinity leads to osmotic and ionic stress and can subsequently cause oxidative stress in plant cells [9]. This process is associated with an increase in the level of reactive oxygen species (ROS), such as singlet oxygen, superoxide, hydroxyl radicals and hydrogen peroxide $[19,20]$. Hydrogen peroxide $\left(\mathrm{H}_{2} \mathrm{O}_{2}\right)$ is one of the most common ROS-synthesized in plant cells and is characterized by high stability compared with other known ROS [21]. Therefore, $\mathrm{H}_{2} \mathrm{O}_{2}$ is commonly used as a marker in the assessment of oxidative stress levels in plant tissues [22]. Under salt stress conditions, increased $\mathrm{H}_{2} \mathrm{O}_{2}$ levels are observed in plant cells [22], which contributes to damage to proteins, nucleic acids and lipids and consequently leads to cell death [23].

ROS synthesis is regulated by cellular antioxidant systems, which consist of enzymes such as: catalase, superoxide dismutase, glutathione peroxidase, ascorbate peroxidase, glutatione-S-transferase, as well as low-molecular-weight compounds, including proline, ascorbic acid, reduced glutathione, $\alpha$-tocopherol, carotenoids, phenolics and flavonoids $[19,21]$. The accumulation of proline in plant cells promotes the maintenance of osmotic balance and the stabilization of subcellular structures (e.g., membranes and protein); furthermore, proline acts as a "scavenger" of free radicals and buffers cellular redox potential under salt stress $[24,25]$.

The inoculation of crops with halotolerant plant growth-promoting endophytic (PGPE) bacteria is considered to be an effective method for increasing the tolerance of plants to salt stress [26-28]. Endophytic bacteria live inside plant tissue without causing pathogenic symptoms [29] and can promote plant growth and development directly (e.g., plant hormones synthesis and, enhanced nutrient uptake) and indirectly (e.g., as biocontrol agents) [30].

The primary objective of the current work was to evaluate the effect of two strains of endophytic bacteria associated with roots of Salicornia europaea on the promotion of growth and salinity tolerance in red beet under various salinity levels. We hypothesized that bioaugmentation of $B$. vulgaris with the selected halotolerant endophytic strains Pseudomonas stutzeri ISE-12 and Kushneria marisflavi CSE-9, isolated from the obligatory halophytic plant S. europaea L., mitigates salt stress in the host plant, while the beneficial effects of inoculation depend on the metabolic properties and salt tolerance ranges of the bacterial strains. The results obtained in this study may help to establish basic selection criteria for plant microbial inoculants in saline areas. 


\section{Materials and Methods}

\subsection{Endophytic Bacteria}

The two halotolerant bacterial strains, P. stutzeri ISE12 and K. marisflavi CSE9, employed in this study were previously isolated from the roots of obligatory halophyte S. europaea and differed in plant growth-promoting metabolic activities [31]. P. stutzeri ISE12 (NCBI AccNo KX035052) was characterized by the presence of the nif $\mathrm{H}$ gene, nitrogen fixation capacity, and siderophore synthesis $\left(\mathrm{W}_{\text {act. }}=48.32\right)$ and indolylacetic acid $\left(15.82 \mu \mathrm{g} \cdot \mathrm{mL}^{-1}\right)$, as well as cellulolytic activity $\left(\mathrm{W}_{\text {act. }}=1.71\right)$. K. marisflavi CSE9 (NCBI AccNo KX027360) exhibited plant growth-promoting (PGP) traits, such as IAA $\left(6.43 \mu \mathrm{g} \cdot \mathrm{mL}^{-1}\right)$ and siderophore production $\left(\mathrm{W}_{\text {act }} 2.86\right)$ [31]. The tolerance of selected strains to different levels of salt stress was evaluated in this work. Bacteria were grown in Luria-Bertanibroth, Lennox (Difco) medium supplemented with different concentrations of NaCl: 0, 50, 100, 150, 200, 300, $400,500,600,700$ and $800 \mathrm{mM}$. The initial OD (optical density) was $5 \times 10^{5}$. Bacteria were cultivated in 96-well microtitration plates, and microbial growth was measured based on the optical density $(\mathrm{OD}=620 \mathrm{~nm})$ after five days (Tecan, Morrisville, USA). Noninoculated media with appropriate concentrations of $\mathrm{NaCl}$ were used as a control.

Bacterial inoculum was prepared from three-day-old cultures incubated on R2A medium (Difco ${ }^{\mathrm{TM}}$ ) supplemented with $2 \% \mathrm{NaCl}$ at $25^{\circ} \mathrm{C}$. Bacterial cells were suspended in $2 \% \mathrm{NaCl}$ solution and diluted to $\mathrm{OD}=0.5$ (OD—optical density, measured at $600 \mathrm{~nm}$, equivalent of $1.5 \times 10^{8} \mathrm{cells} / \mathrm{mL}$ ). Plants were inoculated twice: first inoculation-surface sterilized seeds were incubated (45 min) in bacterial suspension with shaking, second inoculation-two weeks after sowing $1 \mathrm{~mL}$ of bacterial suspension was added in the proximity of the plant root system. Control variant was prepared by treatment of seeds in sterile $2 \% \mathrm{NaCl}$ solution.

\subsection{Plant Material}

Seeds of beetroot (B. vulgaris), Red Ball variety (Torseed ${ }^{\circledR}$, Torun, Poland), were surface-sterilized with a mixture of $70 \%$ ethanol and $30 \%$ hydrogen peroxide $(1: 1,4 \mathrm{~min})$ and washed six times with sterile distilled water. The liquid obtained after the last wash was used to evaluate the efficiency of the sterilization process by plating the rinse on agar plates containing R2A (Difco) and Martin (BTL) medium.

\subsection{Pot Experiment}

B. vulgaris plants were cultivated in three variants of inoculation: control (noninoculated), inoculated with P. stutzeri ISE12, and inoculated with $K$. marisflavi CSE9 and four variants of salinity $(0,50,150$, and $300 \mathrm{NaCl} \mathrm{mM})$ in sterile mixture of sand and vermiculite (1:3). Plants were cultivated in plastic trays $(30 \times 46 \mathrm{~cm})$ containing 54 pots (each pot $-0.0771 ; 5.5 \mathrm{~cm}$ height, $3 \times 3 \mathrm{~cm}$ base width, $4.5 \times 4.5 \mathrm{~cm}$ top width). One tray with 54 plants per each variant was prepared in this experiment. Plants were maintained under controlled environmental conditions (temperature: $24{ }^{\circ} \mathrm{C} \pm 2{ }^{\circ} \mathrm{C}$ and light/dark: 16/8) and irrigated with Hoagland medium (once per week) and distilled water (according to plant requirements) [32]. After eight weeks, plants were collected and analyzed according to Figure 1. 


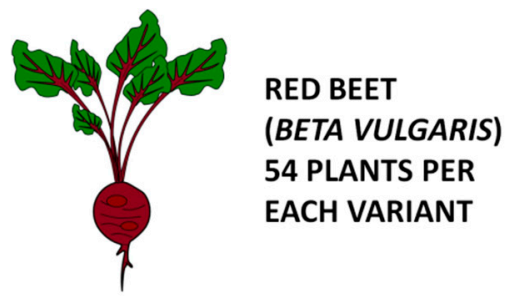

SURFACE STRILIZED SEEDS INCUBATION WITH:

\begin{tabular}{|c|c|c|}
\hline $\begin{array}{c}0,9 \% \text { NACL - CONTROL } \\
\text { VARIANT (NI) }\end{array}$ & PSEUDOMONAS STUTZERI & KUSCHNERIA MARISFLAVI \\
& ISE12 (B1) & \\
\hline
\end{tabular}

\begin{tabular}{|c|c|c|c|}
\hline \multicolumn{4}{|c|}{8 WEEKS CULTIVATION IN DIFFERENT SUBSTRATE SALINITIES: } \\
\hline $0 \mathrm{mM} \mathrm{NaCl}$ & $50 \mathrm{mM} \mathrm{NaCl}$ & $150 \mathrm{mM} \mathrm{NaCl}$ & $300 \mathrm{mM} \mathrm{NaCl}$ \\
\hline
\end{tabular}

ANALYSIS OF:

GROWTH PARAMETERS

- GERMinATION PERCENTAGE (GP)

- GERMINATION INDEX (GI)

- NUMBER OF LEAVES (NL)

- CHLOROPHYLL CONTENT (CH)

- ROOT LENGTH (LR)

- STEM LENGTH (LS)

- FRESH WEIGHT (FW)

- DRY WEIGHT (DW)

\section{BIOCHEMICAL PARAMETERS}

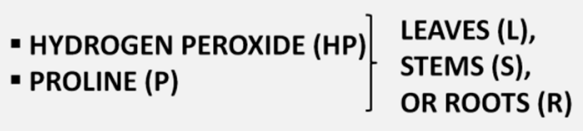

Figure 1. Experimental design.

\subsection{Plant Growth Parameters}

The number of germinated seeds was determined daily (always at the same time) until the end of the 10th day after sowing. The germination percentage (GP) was calculated in accordance with the International Seed Testing Association (ISTA) method:

$$
\mathrm{GP}=\text { number of normally germinated seeds/total number of seeds sown } \times 100
$$

The germination index (GI) was calculated using the following formula:

$$
(\mathrm{GI})=\Sigma\left(\mathrm{G}_{\mathrm{t}} / \mathrm{T}_{\mathrm{t}}\right),
$$

where $G_{t}$ is the number of seeds germinated on day $t$, and $T_{t}$ is the number of days.

After eight weeks of cultivation, the chlorophyll content index (CCI) was measured in the third leaf of each plant (Chlorophyll Content Meter CCM-200, Opti-Sciences, Tyngsboro, MA, USA), as described by Richardson et al. [33]. The obtained CCI values were based on absorbance measurements at 660 and $940 \mathrm{~nm}$ on a surface of $0.71 \mathrm{~cm}^{2}$. 
To evaluate growth parameters, plants were carefully removed from the pots, roots were washed to remove the rest of the growth substrate, and the following parameters were measured: fresh and dry $\left(72 \mathrm{~h}, 85^{\circ} \mathrm{C}, 24 \mathrm{~h}\right)$ weight, root and stem length and number of leaves.

\subsection{Determination of Proline and Hydrogen Peroxide Levels}

In the roots, stems and leaves, the levels of proline and hydrogen peroxide were determined immediately after collecting the plants. The analyses were performed in three biological and three technical replicates (six in total).

The proline level in B. vulgaris organs was assessed according to the methodology proposed by Abraham et al. [34] with modifications. Leaf, stem and root tissues were homogenized in a mortar using liquid nitrogen and extracted with $3 \%(\mathrm{w} / \mathrm{v})$ aqueous sulphosalicylic acid $(5 \mu \mathrm{L} / \mathrm{mg}$ of fresh plant material). The obtained homogenate was transferred to Falcon tubes $(15 \mathrm{~mL})$ and centrifuged at $4{ }^{\circ} \mathrm{C}$, $12,000 \times g$ for $5 \mathrm{~min}$. Then, $100 \mu \mathrm{L}$ of supernatant was added to the previously prepared mixtures containing $100 \mu \mathrm{L} 3 \%$ sulfosalicylic acid, $200 \mu \mathrm{L}$ glacial acetic acid and $200 \mu \mathrm{L}$ acidic ninhydrin reagent. Acidic ninhydrin reagent was prepared as described by Bates et al. [35]. The mixture was mixed and maintained at $96^{\circ} \mathrm{C}$ for $30 \mathrm{~min}$. The reaction was terminated by placing the samples on ice for $3 \mathrm{~min}$. The chromophore was extracted with $1 \mathrm{~mL}$ of toluene and quantified spectrophotometrically at $520 \mathrm{~nm}$. The proline content was evaluated using the standard curve for proline in the concentration range of $0-40 \mu \mathrm{g} / \mathrm{mL}$. Proline concentrations were presented in $\mu \mathrm{g}$ of proline per gram of fresh weight.

Hydrogen peroxide content in plant organs was examined according to Anderson [36] with modifications described by Ngo and Lenhoff [37]. The analysis was performed directly from $0.5 \mathrm{~g}$ of fresh plant material (roots, stems, and leaves), homogenized in liquid nitrogen and extracted with $0.1 \%$ trichloroacetic acid $(5 \mathrm{~mL})$ at $4{ }^{\circ} \mathrm{C}$. The obtained homogenate was transferred to Falcon tubes $(15 \mathrm{~mL})$ and then centrifuged at $4{ }^{\circ} \mathrm{C}, 10,000 \times g$ for $10 \mathrm{~min}$. An aliquot of the supernatant was introduced into new Falcon tubes $(50 \mathrm{~mL})$, neutralized with $0.4 \mathrm{M} \mathrm{KOH}$ to $\mathrm{pH} 7.5$ and centrifuged $(1000 \times g, 1 \mathrm{~min})$. Neutralized supernatant $(200 \mu \mathrm{L})$ was placed in microtiter plate and $50 \mu \mathrm{L} 19.8 \mathrm{mM}$ DMAB in $0.5 \mathrm{M}$ phosphate buffer ( $\mathrm{pH} 6.5), 46 \mu \mathrm{L} 0.456 \mathrm{mM} \mathrm{MBTH}$ and $0.4 \mu \mathrm{L}$ peroxidase $(1 \mathrm{kU} / \mathrm{mL})$ were added. After a 20 min incubation at $25^{\circ} \mathrm{C}$, the $\mathrm{H}_{2} \mathrm{O}_{2}$ content was measured using a Magellan ${ }^{\circledR}$ spectrophotometer at $590 \mathrm{~nm}$. A standard curve was prepared from serial dilutions (range of $0-0.039 \mu \mathrm{M} \mathrm{H}_{2} \mathrm{O}_{2}$ ), and the final $\mathrm{H}_{2} \mathrm{O}_{2}$ concentration was calculated and expressed in nmoles $\mathrm{g}^{-1}$ of fresh weight (FW) of plant material (roots, stems, leaves).

\subsection{Statistical Analysis}

The obtained results are presented as the mean with standard error values for growth (4-50 replicates) and biochemical (three random replicates) parameters. To determine differences among treatments, parametric ANOVA with Tukey post hoc comparisons $(p<0.05)$ was performed. The statistical analyses were performed using the Statistica 10.0 software package, StatSoft 2006. Evaluation of the effect of inoculation (P. stutzeri ISE12 and K. marisflavi CSE9) on the growth and biochemical parameters of $B$. vulgaris was performed by multivariate statistical analysis-a principal component analysis (PCA) (Canoco 5.0) [38].

\section{Results}

\subsection{Salinity Tolerance of Bacterial Strains}

Analysis of the tolerance to salinity revealed significantly higher growth of P. stutzeri ISE12 in comparison to K. marisflavi CSE9 in all studied variants of our experiment (Table S1). The highest growth of P. stutzeri ISE12 was observed in salinity corresponding to $150-600 \mathrm{mM}$ of $\mathrm{NaCl}$. Significant growth inhibition of P. stutzeri ISE12 was observed in media containing $800 \mathrm{mM} \mathrm{NaCl}$. Optimal conditions for K. marisflavi CSE9 growth were observed in the range of $150-800 \mathrm{mM} \mathrm{NaCl}$, while the lack of $\mathrm{NaCl}$ in the medium significantly inhibited bacterial growth (Table S1). K. marisflavi CSE9 was characterized by 
higher salt stress tolerance than P. stutzeri ISE12 based on an analysis comparing bacterial growth in $\mathrm{NaCl}$ supplemented media with the growth of bacteria in a control media (without $\mathrm{NaCl}$ ) expressed as percentage growth inhibition or stimulation (Figure 2).

\section{Salinity tolerance of bacterial strains}

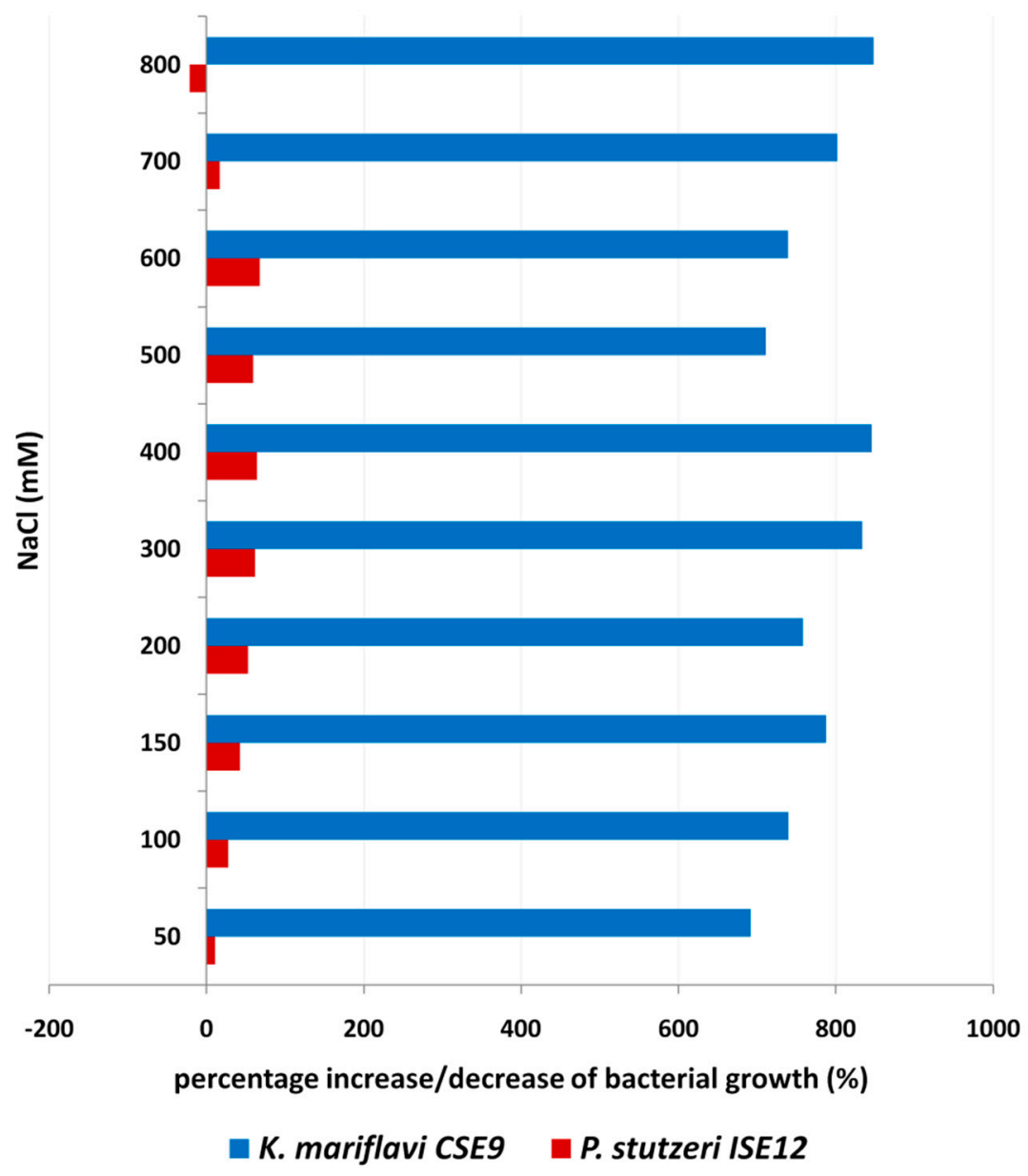

Figure 2. Growth of P. stutzeri ISE12 and K. marisflavi CSE9 in media supplemented with different $\mathrm{NaCl}$ concentrations (50-800 $\mathrm{mM}$ ) was expressed as a percentage increase/decrease compared to bacterial growth in media without salt.

\subsection{Inoculation Effect on Germination and Growth Parameters}

The positive influence of the two selected PGPEs (P. stutzeri ISE12 and K. marisflavi CSE9) on the growth of $B$. vulgaris manifested in improvement of seeds germination rate, growth and biochemical parameters (Figures 3 and 4, Tables S2 and S4) in the absence and presence of salt. Alleviation of the negative effects of salt stress on the plant was observed in all investigated growth parameters, including germination percentage and index, chlorophyll content, number of leaves, length of roots, stem, fresh and dry weight, in comparison to their noninoculated variants (control) (Figure 3, Table S3). The K. marisflavi CSE9 strain was more efficient in promoting overall plant growth and development than P. stutzeri ISE12 (Figure 3). K. marisflavi CSE9 inoculation significantly increased the seed germination rate and germination index at all salt concentrations compared to the noninoculated controls and P. stutzeri ISE12 inoculations. Plants inoculated with K. marisflavi CSE9 showed significantly enhanced growth parameters at all the tested salinity levels (with the exception of chlorophyll level at $150 \mathrm{mM}$ $\mathrm{NaCl}$ and stem length at 0,50 and $300 \mathrm{mM} \mathrm{NaCl}$ ) compared to the noninoculated variants (Figure 3). 
The obtained values were several times higher for the roots length (4.3-11.2), fresh (5.3-7.6) and dry weight (5.5-11.5) of K. marisflavi CSE9-inoculated plants. (Figure 3).

control $\quad$ P. stutzeri ISE-12

\section{K. marisflavi CSE-9}
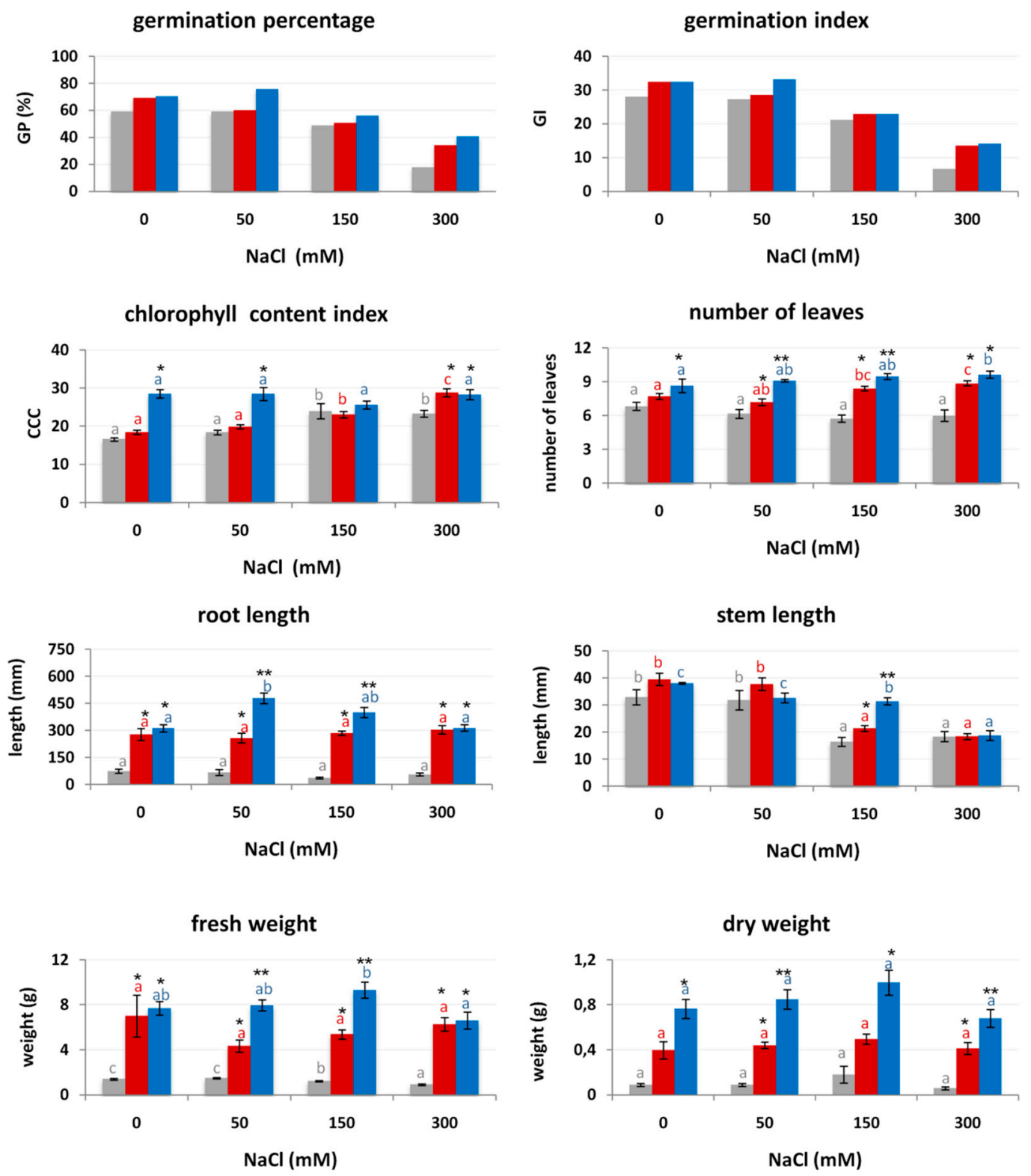

Figure 3. Growth parameters (germination percentage and index, number of leaves, chlorophyll content, length of roots and stems, fresh and dry weight) of B. vulgaris inoculated with P. stutzeri ISE-12 and K. marisflavi CSE-9 cultivated in different $\mathrm{NaCl}$ concentrations $(0,50,150$ and $300 \mathrm{mM} \mathrm{NaCl})$. Significant differences (based on $p<0.05, \mathrm{df}$, MS and $p$ value, one-way ANOVA with Tukey post hoc comparisons) between variants of experiment (noninoculated control; inoculated with P. stutzeri ISE-12 and K. marisflavi CSE9) in each $\mathrm{NaCl}$ concentration are denoted by different marks * and **, while the effect of salinity for each variant is marked with different letters (including gray font for control variant, red font in the case of P. stutzeri ISE-12 treated variant and blue font for K. marisflavi CSE-9 inoculated plants). Mean values \pm standard error are presented ( $n=4-55$, depending on the tested parameters). 


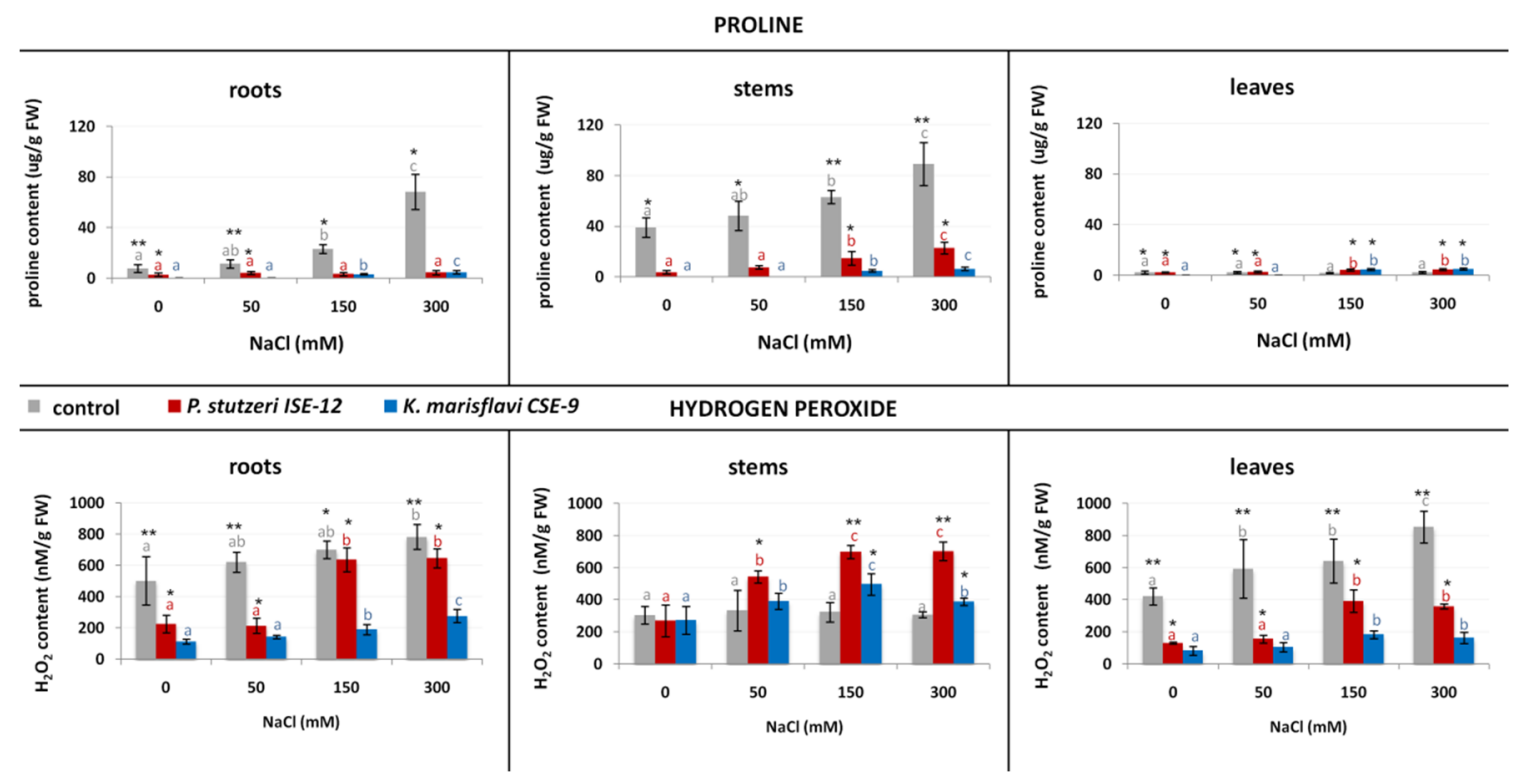

Figure 4. Proline and hydrogen peroxide concentrations in the roots, stems and leaves of the control (noninoculated), P. stutzeri- and K. marisflavi-inoculated B. vulgaris growing in substrates enriched with different $\mathrm{NaCl}$ concentrations $(0,50,150$ and $300 \mathrm{mM})$. Mean values \pm standard deviation are presented $(n=3)$. Significant differences (based on $p<0.05, \mathrm{df}$, MS and $p$ value, one-way ANOVA with Tukey post hoc comparisons) between variants of experiment (noninoculated control; inoculated with $P$. stutzeri ISE-12 and K. marisflavi CSE9) in each $\mathrm{NaCl}$ concentration are denoted by different marks * and **, while effect of salinity for each variant is marked with different letters, including gray font for control variant, orange font in the case of P. stutzeri ISE-12 treated variant and blue font for K. marisflavi CSE-9 inoculated plants).

Inoculation with the $P$. stutzeri ISE12 strain significantly stimulated B. vulgaris root length and fresh weight in all variants of salinity, while the increase in the value of other parameters was related only to selected $\mathrm{NaCl}$ concentrations. In general, the positive effects of $P$. stutzeri ISE12 treatment were observed (with the exception of stem length) on the growth parameters of plants growing in the highest $\mathrm{NaCl}$ concentration (300 mM) (Figure 3).

Substrate salinity led to a decrease in seed germination percentage and index, as well as the length of B. vulgaris stems for all the tested variants (control plants-noninoculated, inoculated plants with $P$. stutzeri ISE12 and K. marisflavi CSE9) (Figure 3). In contrast, an increase in the chlorophyll content in B. vulgaris leaves (plants inoculated with P. stutzeri ISE-12 and control variant) and the number of leaves (in both inoculated variants) was correlated with increasing $\mathrm{NaCl}$ concentration in the growth substrate (Figure 3, Table S3). However, no effect of salt stress was observed with respect to dry weight and root length (with the exception of the variant inoculated with K. marisflavi CSE9). The influence of salinity on fresh weight was dependent on the variants of the experiment (noninoculated-decrease in value related to the increase in the salinity level; variant inoculated with $P$. stutzeri ISE12-no effect; variant inoculated with K. marisflavi CSE9_the highest weight in $150 \mathrm{mM} \mathrm{NaCl}$; Figure 3, Table S3).

\subsection{Inoculation Effect on Biochemical Parameters}

The influence of PGPE inoculation was tested for biochemical parameters, such as proline and hydrogen peroxide levels. The results showed that PGPE inoculation in B. vulgaris reduced the levels of proline (in roots and stems) and hydrogen peroxide (in roots and leaves) compared to the control variants (Figure 4, Table S4). However, the proline content in B. vulgaris leaves differed among the experimental variants. In the case of K. marisflavi CSE-9 inoculated plants, the lowest proline concentrations were observed in those growing in the substrate without $\mathrm{NaCl}(0 \mathrm{mM})$ and that with $50 \mathrm{mM} \mathrm{NaCl}$. In contrast, in the noninoculated plants, the lowest proline levels were detected at higher 
$\mathrm{NaCl}$ concentrations (150 and $300 \mathrm{mM}$ ) (Figure 4, Table S5). The hydrogen peroxide content in stems of B. vulgaris inoculated with P. stutzeri ISE12 in saline substrates $(50300-\mathrm{mM} \mathrm{NaCl})$ was higher than in other variants (control, inoculation with K. marisflavi CSE-9) (Figure 4, Table S4). In general, the levels of proline and hydrogen peroxide in plant organs decreased in the following order: stems $>$ roots $>$ leaves (with the exception of the content of hydrogen peroxide in noninoculated B. vulgaris plants: root and leaves $>$ stems) (Figure 4).

B. vulgaris plants exposed to saline conditions exhibited an increase in proline (except for the variant inoculated with P. stutzeri ISE12-roots, and noninoculated variants-leaves) and hydrogen peroxide (with the exception of noninoculated variant and inoculated with K. marisflavi CSE9-stems) concentrations in the investigated organs associated with increasing substrate salinity (Figure 4, Table S5).

\subsection{Comparison of the Strain Effects}

The principal component analysis (PCA) combined the results of the investigated growth and biochemical parameters obtained for all three variants of the experiment (noninoculated variants, inoculated variants with P. stutzeri ISE12 and K. marisflavi CSE9) revealed visible differences between the control variant (noninoculated) and the other two (Figure 5). The PC1 ordination axis $(56.72 \%$ variation explained) separated the inoculated and noninoculated variants of $B$. vulgaris. The PC2 axis ( $24.01 \%)$ separated the salinity variant of each treatment. There was a positive correlation between the length of the stem, the germination percentage and index and the inoculated variants cultivated in 0 and $50 \mathrm{mM} \mathrm{NaCl}$ (Ps-0, Ps-50, Km-0, Km-50). The dry and fresh weight, root length, number of leaves and chlorophyll level in leaves are associated with the K. marisflavi CSE9 variants at high salinity (150 and $300 \mathrm{mM} \mathrm{NaCl}$ ) (Figure 5). Both inoculated variants at high salinity (Km-300, Ps-150, Ps-300) demonstrated a positive correlation with the level of hydrogen peroxide in stems and the level of proline in leaves (Figure 5). Control variants of $B$. vulgaris grown at lower salinity ( 0 and $50 \mathrm{mM})$ were negatively correlated with the level of chlorophyll and hydrogen peroxide in stems, root length and number of leaves, while variants cultivated at 150 and $300 \mathrm{mM} \mathrm{NaCl}$ (C-150 and C-300) were positively associated with the proline levels in all investigated plant organs and hydrogen peroxide in roots and leaves (Figure 5). The PC1 axis clearly demonstrates the effect of inoculation on the B. vulgaris response. The control variant characterized by the lowest growth and the highest proline and hydrogen peroxide accumulation is opposite to the K. marisflavi CSE9 variants in the ordination diagram. P. stutzeri ISE12 variants occupy the intermediate position (Figure 5). 


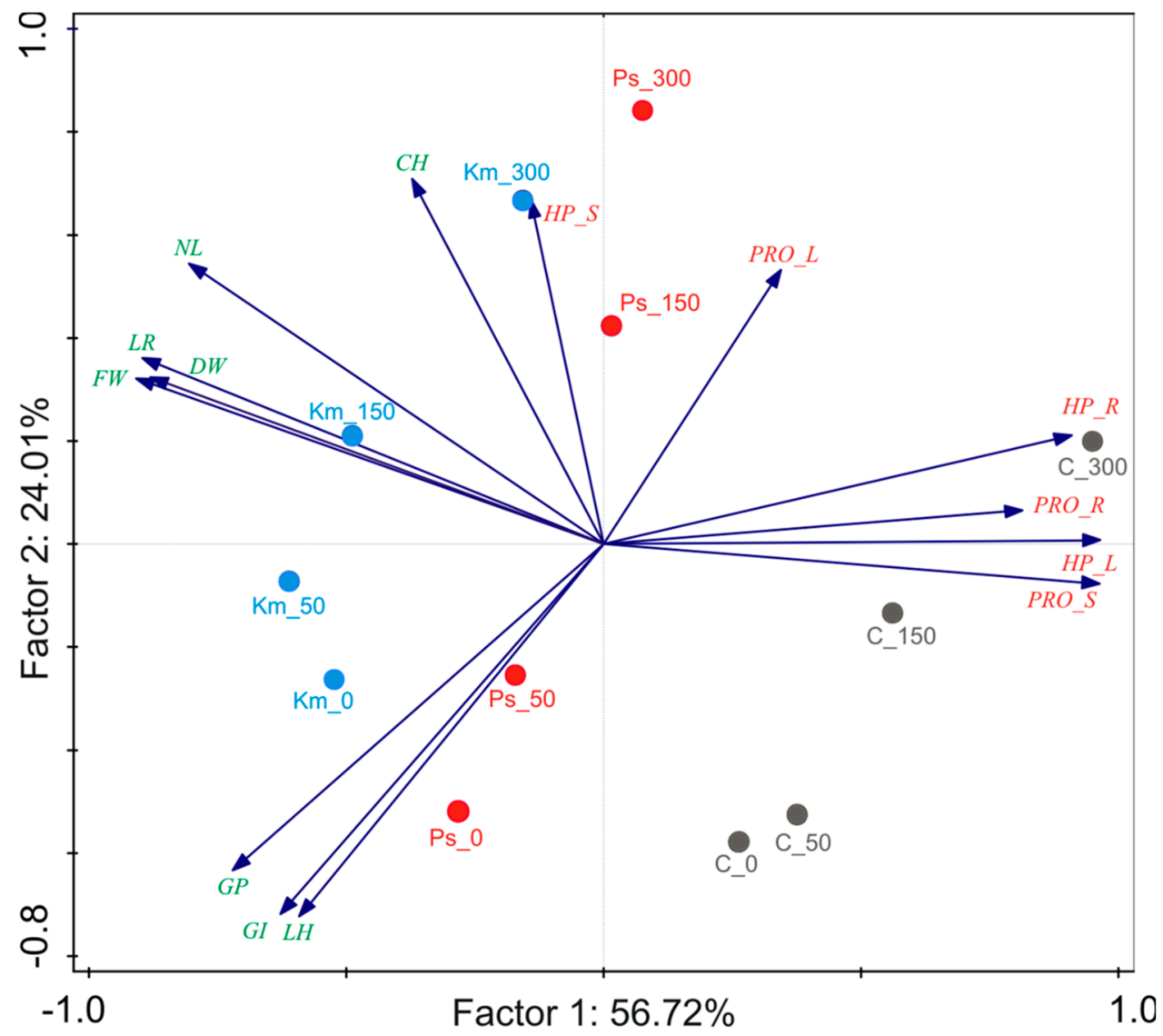

Figure 5. Principal component analysis (PCA) ordination of growth and biochemical parameters of noninoculated $(\mathrm{C})$ and inoculated with P. stutzeri ISE12 (Ps) and K. marisflavi CSE9 (Km) B. vulgaris cultivated at different $\mathrm{NaCl}$ concentrations $(0,50,150,300 \mathrm{mM} \mathrm{NaCl})$. Abbreviations: GP: germination percentage, GI: germination index, NL: number of leaves, $\mathrm{CH}$ : chlorophyll content, LR: length of roots, LS: length of stems, FW: fresh weight, DW: dry weight, PRO: proline, HP: hydrogen peroxidation level, R: root, S: stem, L: leaves.

\section{Discussion}

\subsection{Effect of Salinity on the Growth and Biochemical Parameters of B. vulgaris}

The detrimental impact of salinity on plants manifests in osmotic, ionic and oxidative stress which, in turn, cause several changes in metabolic and physiological processes [39]. A negative influence of salinity on several growth and biochemical parameters of B. vulgaris was observed in our study. We did not observe adverse effects of salt stress in the case of chlorophyll content, number of leaves, length of roots, or dry weight, which was surprising due to the widely known unfavorable effect of salinity on plant growth [40-44]. However, B. vulgaris exhibits high innate tolerance to salinity, which probably results from genetic similarity to its halophytic ancestor, the sea beet $[45,46]$. The most detrimental impact of salinity was observed in the case of germination percentage and index. Germination is a crucial point in seedling formation, determining the health and vigor of a plant [47]. A decrease in germination was observed in the case of different $B$. vulgaris genotypes, which is in line with our results $[13,48]$. In addition to the inhibition of $B$. vulgaris seed germination, salinity disrupted the growth of stems. The highest concentration of $\mathrm{NaCl}(300 \mathrm{mM})$ significantly decreased the length of stems. Shoot growth reduction is one of the known mechanisms of plant response to salt stress and is probably connected with hormonal signals generated by the roots [49]. It might be expected that the roots that are directly exposed to salt will be more vulnerable, but they are characterized by a 
surprisingly robust and relatively good ionic status [49]. The higher sensitivity of stems to salinity compared to roots was confirmed in several reports [28,49-51].

Good tolerance of $B$. vulgaris to salt stress was confirmed by our results. The increase in proline level associated with an increase in substrate salinity was observed primarily in the case of stems and roots regardless of the variant. According to Wu et al. salinity caused a more significant increase in the level of proline in the shoots than in the roots of three sugar beet cultivars [52]. The accumulation of compatible solutes, including proline, is a very important defense mechanism against salinity stress and is responsible for intracellular osmotic equilibrium maintaining [52,53]. An increase in proline levels in plants growing under salt stress was observed in different plant species, including canola (Brassica napus), dill (Anethum graveolens), mulberry (Morus alba cv Khonpai), pistachio (Pistacia vera L.) and Jerusalem artichoke (Helianthus tuberosus) [28,39,54-57]. The accumulation of proline in plants growing under salt stress is associated with the low activity of antioxidant enzymes [58], which is accompanied by an increase in the level of ROS [21,59]. The increase in hydrogen peroxide concentration in response to salt stress was observed with other plant species, e.g., mung bean (Vigna radiata), rice (Oryza sativa), and mulberry (Morus sp.) [54,60,61]. The results of our study indicated a positive correlation between the level of hydrogen peroxide in roots, stems and leaves of $B$. vulgaris and $\mathrm{NaCl}$ concentration. The rise of hydrogen peroxide is usually associated with impairment of cell homeostasis, but $\mathrm{H}_{2} \mathrm{O}_{2}$ also acts as a central player in stress signal transduction pathways responsible for the activation of multiple acclimatory responses $[59,62]$. The studied red beet was able to maintain a balance between $\mathrm{H}_{2} \mathrm{O}_{2}$ production and scavenging in a less saline environment $(50 \mathrm{mM})$. A significant effect of salinity could be observed only at higher $\mathrm{NaCl}$ concentrations (150 and $300 \mathrm{mM}$ ). These observations demonstrate the high tolerance of $B$. vulgaris to salt stress.

\subsection{Effect of K. marisflavi CSE9 and P. stutzeri ISE12 Bioaugmentation on the Growth and Biochemical Parameters of $B$. vulgaris}

Inoculation of plants with PGPE is a notably cost-effective and ecologically sensitive technique that is helpful in salt stress alleviation and the improvement of crop yield [63,64]. Bioaugmentation of B. vulgaris with P. stutzeri ISE12 and K. marisflavi CSE9, which was performed in this study, enhanced all studied growth parameters regardless of $\mathrm{NaCl}$ concentration. Furthermore, bioaugmentation with selected PGPEs caused significant enhancement of plant root length and fresh weight in the presence of $\mathrm{NaCl}$ compared to noninoculated plants. It was shown that salinity causes a reduction in endogenous levels of phytohormones, including auxins, gibberellins, jasmonic acid and salicylic acid, some of which play crucial roles in the growth of roots [65]. A strong correlation between a decline in phytohormones level and reduction in plant root length was noted by Egamberdieva [66,67]. There are also reports on the beneficial influence of exogenous phytohormones application on root system enlargement in plants growing under salt stress [47,68]. IAA-synthesizing bacteria are preferred in promoting plant growth in saline conditions. For example, bacterial IAA plays a major role in salt stress tolerance and stimulates resistance against fungal pathogens of cotton [65]. Briefly, the application of IAA to plants undergoing salt stress stimulates their growth, and cell enlargement improves protein content, promotes stem and hypocotyl elongation, increases height and dry weight, and promotes the development of the root system and seedling fresh and dry weight $[47,69,70]$. As the tested bacterial strains belong to genera able to produce IAA, we suggest, that they may contribute to salt stress alleviation in B. vulgaris by IAA level modification.

The inoculation of B. vulgaris with P. stutzeri ISE12 and K. marisflavi CSE9 affected proline levels in roots and stems and, to a lesser degree, in leaves, which was probably observed because leaves have the greatest distance from the stressful factor. Decreased in proline content in PGPB-inoculated and salt-stressed plants, indicate that the synthesis of osmotically active substances was not enhanced despite the presence of the salt. This finding has been reported by many scientists and was connected with the alleviation of salt stress [26,71]. We propose that the PGPE strains used by us activate a mechanism responsible for salt stress alleviation that is different from the stimulation of proline synthesis. 
Proline synthesis is the reaction to the osmotic component of the salt stress. Since the increase in proline content is prevented by bacterial inoculation, it may be suggested that bacteria mitigate the osmotic stress. Consequently, the osmotic adjustment is not required since the synthesis of osmoprotective substances (including proline) is restricted, the energetic cost of acclimation to salinity is reduced. Saved resources may be redirected support processes of growth and development. Resolving the underlying mechanism will require further experiments. Osmotic stress is triggered by the salt present in the soil and it results in decrease in water uptake by roots. Therefore, it is plausible that the bacteria-dependent, osmotic stress alleviation is due to some mechanism(s) facilitating water uptake from the salinized soil. Studying water relation in plants will be required to address this issue. The increase in proline content and decrease in $\mathrm{H}_{2} \mathrm{O}_{2}$ in chickpea plants bioaugmentated with Mesorhizobium ciceri and Bacillus subtilis were related to the adaptation of their saline stress mechanisms [72]. It is widely known that salt stress stimulates plant ROS production and that PGPE can reduce their synthesis and indirectly protect membrane lipids from peroxidation [72]. The positive effects of bioaugmentation with different PGPB species, e.g., Bacillus subtilis and Pseudomonas frederiksbergensis OS261, on $\mathrm{H}_{2} \mathrm{O}_{2}$ decreased under salt stress conditions, which was observed in different plants, such as chickpea and caliph media [3,73]. In our study, B. vulgaris inoculated with P. stutzeri ISE12 or K. marisflavi CSE9 were characterized by lower levels of hydrogen peroxide in roots and leaves under both growth conditions (nonsaline and saline: 50, 150, and $300 \mathrm{mM} \mathrm{NaCl}$ ). Interestingly, our results are consistent regarding the beneficial effects of the bioaugmentation of plants with selected endophytes, while contradicting results were obtained for the levels of $\mathrm{H}_{2} \mathrm{O}_{2}$ in stems. We assume that the higher concentration of $\mathrm{H}_{2} \mathrm{O}_{2}$ in the stems of inoculated plants compared to the control variant may be associated with a more advanced lignification process, but further studies are warranted to investigate this possibility [74].

Selected endophytes strongly stimulated B. vulgaris growth, leading to better overall conditions, but the effect was strain-specific. The positive effect of P. stutzeri ISE12 had already been demonstrated in the case of rape and beet growing under high-salinity conditions $[13,28]$. In general, there are many scientific reports indicating the beneficial influence of Pseudomonas species on plant growth under salt stress conditions [73,75-78]; however, there are no studies considering the effect of Kushneria sp. As revealed in our earlier studies, $P$. stutzeri ISE12 possesses more plant growth-promoting properties (e.g., $\mathrm{N}_{2}$ fixation, synthesis of siderophores and IAA, and cellulolytic activity) than K. marisflavi CSE9, for which only selected activities were noted (e.g., synthesis of IAA and siderophores) and at a considerably lower level. However, a stronger beneficial influence on the growth and biochemical parameters was observed for plants inoculated with K. marisflavi CSE9 than P. stutzeri ISE12. This may be explained by the fact that $K$. marisflavi occurs inside halophytes, where it probably plays an important role in plant adaptation to the saline environment $[31,79,80]$. This halotolerant strain likely evolved a wider range of adaptation mechanisms for survival in salt-affected environments and heavily synthesizes compounds that are important in promoting plant growth under abiotic stress conditions. It is possible that K. marisflavi CSE9 has other metabolic traits that we did not study. For example, inorganic phosphorus solubilization capacity was observed in the case of halotolerant Kushneria sp. YCWA18 isolated from the sediment of the Daqiao saltern (China) [81]. It is also possible that $K$. marisflavi CSE9 forms a stronger symbiotic interaction with $B$. vulgaris. In summary, we showed that red beet bioaugmentation with halotolerant endophytic bacteria K. marisflavi or P. stutzeri alleviates salt stress and improves biochemical and growth parameters.

\section{Conclusions}

Salinity negatively influences B. vulgaris growth and development, which is confirmed through our results on plant growth parameters and biochemical analysis. Nevertheless, this plant species has a high tolerance to salt stress, as can be observed in the various investigated parameters (e.g., stem length, germination percentage and index, and proline content), and the strongest effects of salinity on the plant were seen at the highest $\mathrm{NaCl}$ concentration $(300 \mathrm{mM})$ in the substrate. 
Bioaugmentation of $B$. vulgaris with both selected PGPE strains mitigated the adverse effects of salinity, leading to increased plant growth and a decrease in proline and hydrogen peroxide concentrations in plant organs. The present study demonstrated that K. marisflavi CSE9, characterized by higher salinity tolerance, is more effective in reducing salt stress in B. vulgaris than is the less salt-tolerant endophyte P. stutzeri ISE12. This study is the first to consider the role of K. marisflavi in plant growth promotion and development, as well as in alleviating salt stress in plants. These results indicate that this strain represents a very valuable resource for future research attempting to identify alternative methods for sustainable crop production.

Supplementary Materials: The following are available online at http://www.mdpi.com/2073-4395/10/10/1571/s1, Table S1: Salt tolerance of $P$. stutzeri ISE12 and K. marisflavi CSE9 growth in media supplemented with different $\mathrm{NaCl}$ concentrations $(0-800 \mathrm{mM})$. Mean \pm standard deviation are presented $(n=4-6)$. Significant differences between salinity treatments (ANOVA, $p<0.05$, with Tukey's comparisons) were marked with different letters; Table S2: Effect of B. vulgaris bioaugmentation (three variants of experiment: 1. control: noninoculated, 2. inoculated with P. stutzeri ISE-12 and 3. inoculated with K. marisflavi CSE9 were considered) using one-way ANOVA. Df value, MS effect, $\mathrm{F}$ value and $p$ level for growth parameters of plants cultivated in different $\mathrm{NaCl}$ concentrations $(0,50,150$ and $300 \mathrm{mM} \mathrm{NaCl})$ are presented; Table S3: Salt stress effect (four $\mathrm{NaCl}$ concentrations: 0, 50, 150 and $300 \mathrm{mM} \mathrm{NaCl}$ were considered) using one-way ANOVA: df value, MS effect, F value and $p$ level for growth parameters of $B$. vulgaris cultivated in three variants of experiment: 1. control: noninoculated, 2 . inoculated with P. stutzeri ISE-12 and 3. inoculated with K. marisflavi CSE9) are presented; Table S4: Effect of B. vulgaris bioaugmentation. Three variants of experiment were considered using one-way ANOVA: 1 . control: noninoculated, 2. inoculated with P. stutzeri ISE-12 and 3. inoculated with K. marisflavi CSE9. Df value, MS effect, F value and $p$ level for biochemical parameters (hydrogen peroxide and proline concentrations) in leaves, stems and roots of plants cultivated in different $\mathrm{NaCl}$ concentrations $(0,50,150$ and $300 \mathrm{mM} \mathrm{NaCl})$ are presented; Table S5: Salt stress effect (four $\mathrm{NaCl}$ concentrations: 0, 50, 150 and $300 \mathrm{mM} \mathrm{NaCl}$ were considered) using one-way ANOVA. Df value, MS effect, F value and $p$ level for biochemical parameters (hydrogen peroxide and proline concentrations) in leaves, stems and roots of B. vulgaris cultivated in three variants of experiment (1. control: noninoculated, 2. inoculated with P. stutzeri ISE-12 and 3. inoculated with K. marisflavi CSE9) are presented.

Author Contributions: S.S. performed the pot experiment, plant growth parameters analysis, biochemical and statistical analysis and wrote the first version of the manuscript. J.T. analyzed biochemical parameters and participated in the preparation of the manuscript. A.P. performed the plant growth parameters and statistical analysis. M.S. and J.M. participated in the preparation of the manuscript. H.K. determined the first concept of the experiment and participated in the preparation of the manuscript. All authors have read and agreed to the published version of the manuscript.

Funding: This research was funded by a grant from the National Science Centre (Poland) (DEC-2012/07/B/NZ9/01801).

Acknowledgments: The authors are very grateful to Marta Lis and Agnieszka Wojciechowska from the Chair of Geobotany and Landscape Planning (Faculty of Biological and Veterinary Sciences, Nicolaus Copernicus University in Torun, Poland) for their help in growth parameter analysis.

Conflicts of Interest: The authors declare no conflict of interest. The funders had no role in the design of the study; in the collection, analyses, or interpretation of data; in the writing of the manuscript, or in the decision to publish the results.

\section{References}

1. Shrivastava, P.; Kumar, R. Soil salinity: A serious environmental issue and plant growth promoting bacteria as one of the tools for its alleviation. Saudi J. Biol. Sci. 2015, 22, 123-131. [PubMed]

2. Gharsallah, C.; Fakhfakh, H.; Grubb, D.; Gorsane, F. Effect of salt stress on ion concentration, proline content, antioxidant enzyme activities and gene expression in tomato cultivars. AOB Plants 2016, 8, plw055. [PubMed]

3. Abd Allah, E.F.; Alqarawi, A.A.; Hashem, A.; Radhakrishnan, R.; Al-Huqail, A.A.; Al-Otibi, F.O.N.; Malik, J.A.; Alharbi, R.I.; Egamberdieva, D. Endophytic bacterium Bacillus subtilis (BERA 71) improves salt tolerance in chickpea plants by regulating the plant defense mechanisms. J. Plant Interac. 2018, 13, 37-44.

4. Kumar, M.; Kumar, R.; Jain, V.; Jain, S. Differential behavior of the antioxidant system in response to salinity induced oxidative stress in salt-tolerant and salt-sensitive cultivars of Brassica juncea L. Biocatal. Agric. Biotechnol. 2018, 13, 12-19.

5. Acosta-Motos, J.R.; Ortuño, M.F.; Bernal-Vicente, A.; Diaz-Vivancos, P.; Sanchez-Blanco, M.J.; Hernandez, J.A. Plant responses to salt stress: Adaptive mechanisms. Agronomy 2017, 7, 18. [CrossRef]

6. Munns, R.; Tester, M. Mechanisms of salinity tolerance. Annu. Rev. Plant Biol. 2008, 59, 651-681. 
7. Shin, W.; Siddikee, A.; Joe, M.M.; Benson, A.; Kim, K.; Selvakumar, G.; Kang, Y.; Jeon, S.; Samaddar, S.; Chatterjee, P.; et al. Halotolerant plant growth promoting bacteria mediated salinity stress amelioration in plants. Korean J. Soil Sci. Fert. 2016, 49, 355-367.

8. Singh, M.; Kumar, J.; Singh, V.P.; Prasad, S.M. Plant tolerance mechanizm against salt stress: The nutrient management approach. Biochem. Pharm. 2014, 3, 5.

9. Liang, W.; Ma, X.; Wan, P.; Liu, L. Plant salt-tolerance mechanism: A review. Biochem. Bioph. Res. Commun. 2018, 495, 286-291.

10. Wruss, J.; Waldenberger, G.; Huemer, S.; Uygun, P.; Lanzerstorfer, P.; Müller, U.; Höglinger, O.; Weghuber, J. Compositional characteristics of commercial beetroot products and beetroot juice prepared from seven beetroot varieties grown in upper Austria. J. Food Compos. Anal. 2015, 42, 46-55.

11. Kapadia, G.J.; Rao, G.S. Anticancer effects of red beet pigments. In Red Beet Biotechnology: Metabolites for Food and Pharmaceutical Applications, 1st ed.; Neelwarne, B., Ed.; Springer: New York, NY, USA, 2013; pp. $124-154$.

12. Clifford, T.; Howatson, G.; West, D.J.; Stevenson, E.J. The potential benefits of red beetroot supplementation in health and disease. Nutrients 2015, 7, 2801-2822. [CrossRef] [PubMed]

13. Piernik, A.; Hrynkiewicz, K.; Wojciechowska, A.; Szymańska, S.; Lis, M.I.; Muscolo, A. Effect of halotolerant endophytic bacteria isolated from Salicornia europaea L. on the growth of fodder beet (Beta vulgaris L.) under salt stress. Arch. Agron. Soil Sci. 2017, 63, 1404-1418. [CrossRef]

14. Sairam, R.; Tyagi, A. Physiology and molecular biology of salinity stress tolerance in plants. Curr. Sci. 2004, $86,407-421$.

15. Bybordi, A. The influence of salt stress on seed germination, growth and yield of canola cultivars. Not. Bot. Horti Agrob. 2010, 38, 128-133.

16. Mane, A.V.; Deshpande, T.V.; Wagh, V.B.; Karadge, B.A.; Samant, J.S. A critical review on physiological changes associated with reference to salinity. IJEST 2011, 6, 1192-1216.

17. Alavi, M.H.; Ranjbar, G.A. Effects of different levels of salinity on germination, proline contents and a-, b- chlorophylls in rapessed (Brassica napus L.). IJACS 2012, 4, 1055-1059.

18. Maurya, V.K.; Gothandam, K.M. Factors influencing the salt stress tolerance in plants-An overview. Res. J. Biotech. 2014, 9, 79-88.

19. Gupta, B.; Huang, B. Mechanism of salinity tolerance in plants: Physiological, biochemical, and molecular characterization. Int. J. Genom. 2014, 2014, 701596. [CrossRef]

20. Schmitt, F.J.; Renger, G.; Friedrich, T.; Kreslavski, V.D.; Zharmukhamedov, S.K.; Los, D.A.; Kuznetsov, V.V.; Allakhverdiev, S.I. Reactive oxygen species: Reevaluation of generation, monitoring and role in stress-signalingin phototrophic organisms. BBA 2014, 1837, 835-848. [CrossRef]

21. Das, K.; Roychoudhury, A. Reactive oxygen species (ROS) and response of antioxidants as ROS-scavengers during environmental stress in plants. Front. Environ. Sci. 2014, 2, 53. [CrossRef]

22. Sharma, P.; Jha, A.B.; Dubey, R.S.; Pessarakli, M. Reactive oxygen species, oxidative damage, and antioxidative defense mechanism in plants under stressful conditions. J. Bot. 2012, 2012, 1-26. [CrossRef]

23. Bienert, G.P.; Schjoerring, J.K.; Jahn, T.P. Membrane transport of hydrogen peroxide. Biochim. Biophys. Acta 2006, 1758, 994-1003. [CrossRef]

24. Hayat, S.; Hayat, Q.; Alyemeni, M.N.; Wani, A.S.; Pichtel, J.; Ahmad, A. Role of proline under changing environments: A review. Plant Signal. Behav. 2012, 7, 1456-1466. [CrossRef] [PubMed]

25. Dar, M.I.; Naikoo, M.I.; Rehman, F.; Naushin, F.; Khan, F.A. Proline accumulation in plants: Roles in stress tolerance and plant development. In Osmolytes and Plants Acclimation to Changing Environment: Emerging Omicstechnologies; Iqbal, N., Nazar, R., Khan, N.A., Eds.; Springer: New Delhi, India, 2016; pp. 155-166.

26. Jha, Y.; Subramanian, R.B.; Patel, S. Combination of endophytic and rhizospheric plant growth promoting rhizobacteria in Oryza sativa shows higher accumulation of osmoprotectant against saline stress. Acta Physiol. Plant. 2011, 33, 797-802. [CrossRef]

27. Zhao, S.; Zhou, N.; Zhao, Z.Y.; Zhang, K.; Wu, G.H.; Tian, C.Y. Isolation of endophytic plant growth-promoting bacteria associated with the halophyte Salicornia europaea and evaluation of their promoting activity under salt stress. Curr. Microbiol. 2016, 73, 574-581. [CrossRef] [PubMed]

28. Szymańska, S.; Dabrowska, G.; Tyburski, J.; Niedojadło, K.; Piernik, A.; Hrynkiewicz, K. Boosting the Brassica napus L. tolerance to salinity by the halotolerant strain Pseudomonas stutzeri ISE12. Environ. Exp. Bot. 2019, 163, 55-68. [CrossRef] 
29. Batra, P.; Barkodia, M.; Ahlawat, U.; Sansanwal, R.; Sharma, T.; Wati, L. Endophytes: An environmental friendly bacteria for plant growth promotion. Int. J. Curr. Microbiol. Appl. Sci. 2018, 7, 1899-1911. [CrossRef]

30. Reyad, A.M.M.; Radwan, T.E.E.; Hemida, K.A.; Al-Qassem, N.A.A.; Ali, R.M. Salt tolerant endophytic bacteria from carthamus tinctorius and their role in plant salt tolerance improvement. Int. J. Curr. Sci. Res. 2017, 3, 1467-1488.

31. Szymańska, S.; Płociniczak, T.; Piotrowska-Seget, Z.; Hrynkiewicz, K. Endophytic and rhizosphere bacteria associated with the roots of the halophyte Salicornia europaea L.-Community structure and metabolic potential. Microbiol. Res. 2016, 192, 37-51.

32. Hoagland, D.R.; Arnon, D.I. The water-culture method for growing plants without soil. Calif. Agric. Exp. Stn. Circ. 1950, 347, 36-39.

33. Richardson, A.D.; Duigan, P.S.; Berlyn, G.P. An evaluation of noninvasive methods to estimate foliar chlorophyll content. New Phytol. 2002, 153, 185-194. [CrossRef]

34. Abraham, E.; Hourton-Cabassa, C.; Erdei, L.; Szabados, L. Method for detrmination of proline in plants. Methods Mol. Biol. 2010, 639, 317-331. [PubMed]

35. Bates, L.; Waldren, R.P.; Teare, I.D. Rapid determination of free proline for water-stress studies. Plant Soil 1973, 39, 205-207. [CrossRef]

36. Anderson, J.A. Catalase activity, hydrogen peroxide content and thermotolerance of pepper leaves. Sci. Hortic. 2002, 95, 277-284. [CrossRef]

37. Ngo, T.T.; Lenhoff, H.M. A sensitive and versatile chromogenic assay for peroxidase and peroxidase-coupled reactions. Anal. Biochem. 1980, 105, 389-397. [CrossRef]

38. Ter Braak, C.J.F.; Smilauer, P. Canoco Reference Manual and User's Guide: Software for Ordination; Microcomputer Power: Ithaca, NY, USA, 2012.

39. Rahneshan, Z.; Nasibi, F.; Moghadam, A.A. Effects of salinity stress on some growth, physiological, biochemical parameters and nutrients in two pistachio (Pistacia vera L.) rootstocks. J. Plant Interact. 2018, 1, 73-82.

40. Ashraf, M.; Athar, H.R.; Harris, P.J.C.; Kwon, T.R. Some prospective strategies for improving crop salt tolerance. Adv. Agron. 2008, 97, 45-110.

41. Bhatt, M.J.; Patel, A.D.; Bhatti, P.M.; Pandey, A.N. Effect of soil salinity on growth, water status and nutrient accumulation in seedlings of Ziziphus mauritiana (Rhamnaceae). J. Fruit Ornam. Plant Res. 2008, 16, 383-401.

42. Bacarin, M.A.; Deuner, S.; Silva, F.S.P.; Cassol, D.; Silva, D.M. Chlorophyll a fluorescence as indicative of the salt stress on Brassica napus L. Braz. J. Plant Physiol. 2011, 23, 245-253. [CrossRef]

43. Ambede, J.G.; Netondo, G.W.; Mwai, G.N.; Musyimi, D.M. NaCl salinity affects germination, growth, physiology, and biochemistry of bambara groundnut. Braz. J. Plant Physiol. 2012, 24, 151-160. [CrossRef]

44. Orhan, F. Alleviation of salt stress by halotolerant and halophilic plant growth-promoting bacteria in wheat (Triticum aestivum). BJM 2016, 47, 621-627. [CrossRef] [PubMed]

45. Rozema, J.; Cornelisse, D.; Zhang, Y.; Li, H.; Bruning, B.; Katschnig, D.; Broekman, R.; Ji, B.; van Bodegom, P. Comparing salt tolerance of beet cultivars and their halophytic ancestor: Consequences of domestication and breeding programmes. Aob Plants 2015, 7, plu083. [CrossRef]

46. Da Silva, A.O.; de Silva, Ê.F.; Klar, A.E. Yield of beet cultivars under fertigation management and salinity control in a protected environment. Chil. J. Agric. Res. 2016, 76, 463-470. [CrossRef]

47. Saeidi, M.; Abdoili, M.; Azhand, M. Effect of foliar application of indole-3-acetic acid (IAA) at the beginning of grain growth (cell division) stage on agronomic characteristics and seedling growth parameters of two bread wheat under water and salinity stresses. Int. J. Biosci. 2014, 5, 244-255.

48. Ghoulam, C.; Fares, K. Effect of salinity on seed germination and early seedling growth of sugar beet (Beta vulgaris L.). Seed Sci. Technol. 2001, 29, 357-364.

49. Munns, R. Comparative physiology of salt and water stress. Plant Cell Environ. 2002, 25, 239-250. [CrossRef]

50. Maas, E.V.; Hoffman, G.J. Crop salt tolerance-Current assessment. J. Irrig. Drain. Div. ASCE 1977, 103, 115-134.

51. Ramoliya, P.J.; Patel, H.M.; Pandey, A.N. Effect of salinization of soil on growth and nutrient accumulation in seedlings of Prosopis Cineraria. J. Plant Nutr. 2006, 29, 283-303. [CrossRef]

52. Wu, G.Q.; Liang, N.; Feng, R.J.; Zhang, J.J. Evaluation of salinity tolerance in seedlings of sugar beet (Beta vulgaris L.) cultivars using proline, soluble sugars and cation accumulation criteria. Acta Physiol. Plant. 2013, 35, 2665-2674. [CrossRef] 
53. Subbarao, G.V.; Wheeler, R.M.; Levine, L.H.; Stutte, G.W. Glycine betaine accumulation, ionic and water relations of red-beet at contrasting levels of sodium supply. J. Plant Physiol. 2001, 158, 767-776. [CrossRef]

54. Harinasut, P.; Srisunak, S.; Pitukchaisopol, S.; Charoensataporn, R. Mechanisms of adaptation to increasing salinity of mulberry: Proline content and ascorbate peroxidase activity in leaves of multiple stems. Sci. Asia 2000, 26, 207-211. [CrossRef]

55. Nazarbeygi, E.; Yazdi, H.L.; Naseri, R.; Soleimani, R. The Effects of different levels of salinity on proline and a-, b- chlorophylls in canola. AEJAES 2011, 10, 70-74.

56. Mehr, Z.S. Salt-induced changes in germination and vegetative stages of Anethum graveolens L. J. StresS Physiol. Biochem. 2013, 9, 189-198.

57. Huang, Z.; Zhao, L.; Chen, D.; Liang, M.; Liu, Z.; Shao, H.; Long, X. Salt Stress encourages proline accumulation by regulating proline biosynthesis and degradation in Jerusalem artichoke plantlets. PLoS ONE 2013, 8, e62085. [CrossRef] [PubMed]

58. Sudhakar, C. Change in the antioxidant enzyme efficacy in two high yielding genotypes of mulberry (Morus alba L.) under $\mathrm{NaCl}$ salinity. Plant Sci. 2001, 161, 613-619. [CrossRef]

59. Hossain, M.A.; Bhattacharjee, S.; Armin, S.M.; Qian, P.; Xin, W.; Li, H.Y.; Burritt, D.J.; Fujita, M.; Tran, L.S.P. Hydrogen peroxide priming modulates abiotic oxidative stress tolerance: Insights from ROS detoxification and scavenging. Front. Plant Sci. 2015, 6, 420. [CrossRef]

60. Kong-ngern, K.; Bunnag, S.; Theerakulpisut, P. Proline, hydrogen peroxide, membrane stability and antioxidant enzyme activity as potential indicators for salt tolerance in rice (Oryza sativa L.). Int. J. Bot. 2012, $8,54-65$.

61. Nahar, K.; Hasanuzzaman, M.; Alam, M.M.; Fujita, M. Roles of exogenous glutathione in antioxidant defense system and methylglyoxal detoxification during salt stress in mung bean. Biol. Plant 2015, 59, 745-756. [CrossRef]

62. Hernandez, M.; Fernandez-Garcia, N.; Diaz-Vivancos, P.; Olmos, E. A different role for hydrogen peroxide and the antioxidative system under short and long salt stress in Brassica oleracea roots. J. Exp. Bot. 2010, 61, 521-535. [CrossRef]

63. Lata, R.; Chowdhury, S.; Gond, S.K.; White, J.F. Induction of abiotic stress tolerance in plants by endophytic microbes. Lett. Appl. Microbiol. 2018, 66, 268-276. [CrossRef]

64. Vaishnav, A.; Shukla, A.K.; Sharma, A.; Kumar, R.; Choudhary, D.K. Endophytic bacteria in plant salt stress tolerance: Current and future prospects. J. Plant Growth Regul. 2018, 38, 650-668. [CrossRef]

65. Egamberdieva, D.; Jabborova, D.; Hashem, A. Pseudomonas induces salinity tolerance in cotton (Gossypium hirsutum) and resistance to Fusarium root rot through the modulation of indole-3-acetic acid. Saudi J. Biol. Sci. 2015, 22, 773-779. [CrossRef] [PubMed]

66. Egamberdieva, D. Alleviation of salt stress by plant growth regulators and IAA producing bacteria in wheat. Acta Physiol. Plant. 2009, 31, 861-864. [CrossRef]

67. Egamberdieva, D. The role of phytohormone producing bacteria in alleviating salt stress in crop plants. In Biotechnological Techniques of Stress Tolerance in Plants; Miransari, M., Ed.; Stadium Press: Houston, TX, USA, 2013; pp. 21-39.

68. El-Metwally, I.M.; Ali, O.A.M.; Abdelhamid, M.T. Response of wheat (Triticum aestivum L.) and associated grassy weeds grown in salt-affected soil to effects of graminicides and indole acetic acid. Agriculture 2015, 61, 1-11. [CrossRef]

69. Navarro-Torre, S.; Mateos-Naranjo, E.; Caviedes, M.A.; Pajuelo, E.; Rodríguez-Llorente, I.D. Isolation of plant-growth-promoting and metal-resistant cultivable bacteria from Arthrocnemum macrostachyum in the odiel marshes with potential use in phytoremediation. Mar. Pollut. Bull. 2016, 110, 133-142. [CrossRef]

70. Yasmin, H.; Naeem, S.; Bakhtawar, M.; Jabeen, Z.; Nosheen, A.; Naz, R.; Keyani, R.; Mumtaz, S.; Hassan, M.N. Halotolerant rhizobacteria Pseudomonas pseudoalcaligenes and Bacillus subtilis mediate systemic tolerance in hydroponically grown soybean (Glycine max L.) against salinity stress. PLoS ONE 2020, 15, e0231348. [CrossRef]

71. Rojas-Tapias, D.; Moreno-Galván, A.; Pardo-Díaz, S.; Obando, M.; Rivera, D.; Bonilla, R. Effect of inoculation with plant growth-promoting bacteria (PGPB) on amelioration of saline stress in maize (Zea mays). Appl. Soil Ecol. 2012, 61, 264-272. [CrossRef] 
72. Egamberdieva, D.; Wirth, S.J.; Shurigin, V.V.; Hashem, A.; Abd_Allah, E.F. Endophytic bacteria improve plant growth, symbiotic performance of chickpea (Cicer arietinum L.) and induce suppression of root rot caused by Fusarium solani under salt stress. Front. Microbiol. 2017, 8, 1887. [CrossRef]

73. Chatterjee, P.; Samaddar, S.; Anandham, R.; Kang, Y.; Kim, K.; Selvakumar, G.; Sa, T. Beneficial soil bacterium Pseudomonas frederiksbergensis OS261 augments salt tolerance and promotes red pepper plant growth. Front. Plant Sci. 2017, 8, 705. [CrossRef]

74. Ros Barceló, A. Hydrogen peroxide production is a general property of the lignifying xylem from vascular plants. Ann. Bot. 1998, 82, 97-103. [CrossRef]

75. Bacilio, M.; Moreno, M.; Bashan, Y. Mitigation of negative effects of progressive soil salinity gradients by application of humic acids and inoculation with Pseudomonas stutzeri in a salt-tolerant and a salt-susceptible pepper. Appl. Soil Ecol. 2016, 107, 394-404. [CrossRef]

76. Kumar, K.; Amaresan, N.; Madhuri, K. Alleviation of the adverse effect of salinity stress by inoculation of plant growth promoting rhizobacteria isolated from hot humid tropical climate. Ecol. Eng. 2017, 102, 361-366. [CrossRef]

77. Deepalaxmi, R.K.; Gayathri, C. Screening of halophilic microorganisms (Oceanobacillus oncorhynchi and Pseudomonas stutzeri) for the effect of plant growth promotion and its formulation as a biofertilizer. SSRG Int. J. Agric. Environ. Sci. 2018, 5, 2394-2568.

78. Lami, M.J.; Adler, C.; Caram-Di Santo, M.C.; Zenoff, A.M.; de Cristobal, R.E.; Espinosa-Urgel, M.; Vincent, P.A. Pseudomonas stutzeri MJL19, a rhizosphere-colonizing bacterium that promotes plant growth under saline stress. J. Appl. Microbiol. 2020, 1364-5072. [CrossRef] [PubMed]

79. Mapelli, F.; Marasco, R.; Rolli, E.; Barbato, M.; Cherif, H.; Guesmi, A.; Ouzari, I.; Daffonchio, D.; Borin, S. Potential for plant growth promotion of rhizobacteria associated with Salicornia growing in Tunisian hypersaline soils. BioMed Res. Int. 2013, 2013, 248078. [CrossRef] [PubMed]

80. Mora-Ruiz, M.D.R.; Font-Verdera, F.; Diaz-Gil, C.; Urdiain, M.; Rodríguez-Valdecantos, G.; González, B.; Orfila, A.; Rosselló-Móra, R. Moderate halophilic bacteria colonizing the phylloplane of halophytes of the subfamily Salicornioideae (Amaranthaceae). Syst. Appl. Microbiol. 2015, 38, 406-416. [CrossRef] [PubMed]

81. Zhu, F.; Qu, L.; Hong, X.; Sun, X. Isolation and characterization of a phosphate-solubilizing halophilic bacterium Kushneria sp. YCWA18 from Daqiao Saltern on the coast of Yellow Sea of China. Evid.-Based Complement. Altern. Med. 2011, 2011, 615032.

Publisher's Note: MDPI stays neutral with regard to jurisdictional claims in published maps and institutional affiliations.

(C) 2020 by the authors. Licensee MDPI, Basel, Switzerland. This article is an open access article distributed under the terms and conditions of the Creative Commons Attribution (CC BY) license (http://creativecommons.org/licenses/by/4.0/). 